\title{
Late stage presentation of HIV-positive patients to antiretroviral outpatient clinic in Zambia
}

\begin{tabular}{|c|c|}
\hline $\begin{array}{l}\text { Authors: } \\
\text { Timothy Mart } \\
\text { Morgan Mwe }\end{array}$ & $\begin{array}{l}n^{1} \text { (1) } \\
n^{2,3,4,5} \text { (1) }\end{array}$ \\
\hline \multicolumn{2}{|c|}{$\begin{array}{l}\text { Affiliations: } \\
{ }^{1} \text { The School of Medicine, } \\
\text { Medical Sciences and } \\
\text { Nutrition, University of } \\
\text { Aberdeen, United Kingdom }\end{array}$} \\
\hline \multicolumn{2}{|c|}{$\begin{array}{l}\text { Zambia Medical Association, } \\
\text { Lusaka, Zambia }\end{array}$} \\
\hline \multicolumn{2}{|c|}{$\begin{array}{l}{ }^{3} \text { Zambia College of } \\
\text { Physicians, Zambia }\end{array}$} \\
\hline \multicolumn{2}{|c|}{$\begin{array}{l}{ }^{4} \text { East Central and Southern } \\
\text { Africa College of Physicians, } \\
\text { Zambia }\end{array}$} \\
\hline \multicolumn{2}{|c|}{$\begin{array}{l}{ }^{5} \text { International Society of } \\
\text { Nephrology, Brussels, } \\
\text { Belgium }\end{array}$} \\
\hline \multicolumn{2}{|c|}{$\begin{array}{l}\text { Corresponding author: } \\
\text { Timothy Martin, } \\
\text { timothy.martin.08@ } \\
\text { aberdeen.ac.uk }\end{array}$} \\
\hline \multicolumn{2}{|c|}{$\begin{array}{l}\text { Dates: } \\
\text { Received: } 09 \text { Jan. } 2017 \\
\text { Accepted: } 18 \text { Aug. } 2017 \\
\text { Published: } 30 \text { Nov. } 2017\end{array}$} \\
\hline \multicolumn{2}{|c|}{$\begin{array}{l}\text { How to cite this article: } \\
\text { Martin T, Mweene M. Late } \\
\text { stage presentation of } \\
\text { HIV-positive patients to } \\
\text { antiretroviral outpatient } \\
\text { clinic in Zambia. S Afr J HIV } \\
\text { Med. 2017;18(1), a717. } \\
\text { https://doi.org/10.4102/ } \\
\text { sajhivmed.v18i1.717 }\end{array}$} \\
\hline \multicolumn{2}{|c|}{$\begin{array}{l}\text { Copyright: } \\
\text { (C) 2017. The Authors. } \\
\text { Licensee: AOSIS. This } \\
\text { is licensed under the } \\
\text { Creative Commons } \\
\text { Attribution License. }\end{array}$} \\
\hline \multicolumn{2}{|l|}{ Read online: } \\
\hline 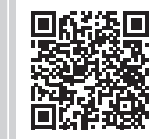 & $\begin{array}{l}\text { Scan this QR } \\
\text { code with your } \\
\text { smart phone or } \\
\text { mobile device } \\
\text { to read online. }\end{array}$ \\
\hline
\end{tabular}

Background: The World Health Organization (WHO) and the Zambian Ministry of Health set out new guidelines on combination antiretroviral therapy (cART) in 2013 expanding the eligibility criteria for patients with HIV.

Objectives: The primary objective were to determine when cART was initiated in HIV-positive outpatients according to clinical and immunological criteria, and to identify what proportion of patients who were eligible for cART according to $2013 \mathrm{WHO}$ and 2013 Zambian cART guidelines were currently on cART.

Methodology: This was a clinical audit of HIV-positive outpatients attending the cART clinic at Ndola Central Hospital in Ndola, Zambia, with retrospective cross-sectional chart review and survey design. Data were collected from clinical records and interviews with patients.

Results: A total of 99\% of patients eligible for cART according to 2013 guidelines were on treatment. Clinical staging of patients at initiated on cART $(n=206)$ was as follows: $28 \%$ clinical stage I, 21\% clinical stage II, 36\% clinical stage III and 15\% clinical stage IV. The median CD4 count when patients were started on cART was 147 cells $/ \mathrm{mm}^{3}$.

Conclusion: The results show that a majority of patients were initiated on cART late in their disease course according to immunological $\left(\mathrm{CD} 4<200 \mathrm{cell} / \mathrm{mm}^{3}\right.$ ) and clinical criteria (stage III or IV). However, the vast majority of patients eligible for cART were currently on treatment. The late initiation of cART appears to be a result of late diagnosis of HIV.

\section{Introduction}

Human immunodeficiency virus (HIV) and acquired immune deficiency syndrome (AIDS) are major causes of morbidity and mortality, with an estimated 36.7 million HIV-infected people worldwide in 2015. ${ }^{1}$ Illness and symptoms associated with HIV are grouped into four clinical stages according to World Health Organization (WHO) criteria, ranging from asymptomatic disease (stage I) to AIDS defining illness (stage IV). ${ }^{2}$ Immunological monitoring of HIV is achieved through a blood test called the CD4 count, which measures the CD4 lymphocytes. There is a strong relationship between CD4 count, immunodeficiency and risk of HIV-related illnesses., ${ }^{3,4}$ Since the late 1980s, various antiretrovirals (ARVs) have been developed which can significantly improve outcomes for people with HIV. ARV drugs are given in combination in triple regimens known as combination antiretroviral therapy (cART). ${ }^{3}$

Zambia is one of the countries most severely affected by the HIV epidemic, with an estimated prevalence of $13.3 \%$ in adults in 2013-2014. ${ }^{5}$ The HIV epidemic in Zambia came to the fore in the 1990s; it was a generalised epidemic with the main method of transmission being heterosexual sex. ${ }^{6}$ There are a variety of factors which could explain the HIV epidemic in Zambia. These include a tendency to have multiple concurrent partners, frequent intergenerational sex, low condom usage and transactional sex. $6,7,8$ The prevalence of HIV in Zambia has decreased from $15.6 \%$ in 2001-2002 to $13.3 \%$ in 2013-2014; however, it remains higher in some regions such as the Copperbelt, where the prevalence was $18.2 \%$ in $2013-2014 .{ }^{5}$

Over the past few years, there have been improvements in HIV testing and counselling (HTC) and HIV education programmes in Zambia. There was an increase in HIV testing in public health facilities from $7.4 \%$ of adults over 15 years tested in 2008 to $18.1 \%$ in 2010, and further increases have occurred since this date under a national HIV policy. ${ }^{5,6}$ Education programmes on HIV in Zambia have helped improve comprehensive knowledge of HIV from $35.9 \%$ in 2007 to $42.4 \%$ in $2013-2014$ in women and from $38.8 \%$ in 2007 to $49.0 \%$ in 2013-2014 in men. ${ }^{5}$ 
Access to cART in low-income countries has improved in recent years in large part because of assistance from The Global Fund to Fight AIDS, Tuberculosis and Malaria, and the President's Emergency Plan for AIDS Relief (PEPFAR). ${ }^{9}$ From 2003, cART was provided free of charge at two centres in Zambia: The University Teaching Hospital in Lusaka and Ndola Central Hospital. This was subsequently expanded to other health facilities throughout Zambia with funding assistance from PEPFAR and the Global Fund, and by 2013, an estimated $82 \%$ of people eligible for cART in Zambia received treatment. ${ }^{6,10}$ The national AIDS strategic framework (NASF) set a target of $90 \%$ of patients eligible for cART to be on treatment by $2015 .{ }^{6}$

The 2013 WHO ART guidelines recommended that patients with clinical stage III or IV, or a CD4 count of less than 500 cells $/ \mathrm{mm}^{3}$ should be started on cART. ${ }^{4}$ In 2013, the Zambian Ministry of Health produced a new set of cART guidelines in accordance with the 2013 WHO ART guidelines. ${ }^{11}$ This study was performed in 2014; in 2015, the WHO released new recommendations, which stipulated that cART should be started in all patients with HIV regardless of their clinical stage or CD4 count. ${ }^{12}$

Zambia offers universal free cART treatment to all HIV-positive people who meet eligibility criteria. The Zambian consolidated guidelines for treatment and prevention of HIV infection 2013 guidelines increased eligibility criteria in accordance with the WHO consolidated guidelines on the use of ARV drugs for treating and preventing HIV infection., ${ }^{4,11}$ Earlier initiation of cART has been shown to improve health outcomes for patients with HIV. ${ }^{13,14,15}$ It is important to audit cART use against these new national and international guidelines to ensure their effective use and identify any areas for improvement.

\section{Methods}

\section{Objectives}

The first primary objective of this study was to audit the proportion of patients eligible for cART according to 2013 WHO ART and 2013 Zambian cART guidelines who had been initiated on CART. The second primary objective was to find when HIV-positive outpatients attending the cART clinic at Ndola Central Hospital were initiated on cART according to CD4 count and clinical criteria. CD4 count at initiation of cART will also be stratified against clinical stage. In addition, a subgroup analysis of those started before 01 January 2010 and those started after 01 January 2010 will be performed. The secondary objectives were to (1) establish which cART regimens patients were currently on, (2) ascertain if these regimens were first-line, (3) audit first-line regimens against guidelines, (4) find changes in regimens and reasons for switching, (5) note side effects from the current regimen, (6) find adherence to CART, (7) find prevalence of risk factors for HIV and (8) check reported condom use.

\section{Study design}

A clinical audit of cART regimens with retrospective crosssectional chart review and survey design.

\section{Data collection}

Information was collected from clinical records and interviews with patients at the adult cART outpatient clinic in Ndola Central Hospital in Ndola, Copperbelt, Zambia. The study population was HIV-positive outpatients attending the adult cART clinic between 11 March 2014 and 07 April 2014. All patients attending the clinic during the study period were invited to participate in the study. The purpose of the study was explained to the patients and written or verbal consent was obtained from patients who wished to participate. In cases where the patient was unable to write their signature but could give verbal informed consent, the data collector noted that verbal consent had been obtained. Patients who did not provide consent were excluded from the study. Information on clinical stage, CD4 count, cART regimens, reasons for changing regimens and side effects from cART was collected from clinical records. Additional information on risk factors for HIV, reported condom use and adherence to medications was collected from interviews with patients. Where patients did not speak English, a translator was used. Information from the data collection sheets was transferred to an Excel spreadsheet for analysis.

\section{Adherence to guidelines}

The 2013 Zambian consolidated guidelines for treatment and prevention of HIV infection and the 2013 WHO consolidated guidelines on the use of ARV drugs for treating and preventing HIV infection both recommend starting cART in any HIV-positive patients with WHO clinical stage III or IV. In addition, these guidelines recommend that patients of any clinical stage with a CD4 count of below 500 cells $/ \mathrm{mm}^{3}$ should also be initiated on cART. ${ }^{4,11}$ Patients were classified as eligible for treatment if they currently met eligibility criteria according to the 2013 guidelines for cART, or if had previously been started on cART according to guidelines at the time of initiation (Table 1). The eligibility criteria for cART have been expanded; therefore, all patients eligible under previous guidelines would be eligible under the 2013 guidelines with the addition of patients who meet the expanded eligibility criteria. This audit monitored the proportion of patients eligible for cART who were currently on cART to establish the adherence to the 2013 guidelines.

ART regimens used in this audit were compared against those recommended as first-line by the 2013 Zambian consolidated cART guidelines and 2013 WHO ART guidelines. The WHO recommended regimens were zidovudine $(\mathrm{AZT})+$ lamivudine $(3 \mathrm{TC})$ + nevirapine (NVP);

TABLE 1: Eligibility criteria for initiation on combination antiretroviral therapy across different time periods.

\begin{tabular}{|c|c|c|c|}
\hline Time period & ART guidelines applied & Clinical stage & $\begin{array}{l}\text { CD4 count } \\
\text { (cells } / \mathrm{mm}^{3} \text { ) }\end{array}$ \\
\hline Before 2010 & 2006 WHO ART guidelines & Clinical stage III or IV & $\leq 200$ \\
\hline $\begin{array}{l}\text { Between } 2010 \\
\text { and } 2013\end{array}$ & 2010 WHO ART guidelines & Clinical stage III or IV & $\leq 350$ \\
\hline 2014 & $\begin{array}{l}2013 \text { WHO ART guidelines; } \\
2013 \text { Zambian consolidated } \\
\text { cART guidelines }\end{array}$ & Clinical stage III or IV & $\leq 500$ \\
\hline
\end{tabular}

ART, antiretroviral; WHO, World Health Organization. 
tenofovir disoproxil fumarate (TDF) + 3TC [or emtricitabine (FTC)] + efavirenz (EFV) and TDF + 3TC (or FTC) NVP; with a preference for TDF + 3TC (or FTC) + EFV. ${ }^{4}$ The 2013 Zambian consolidated cART guidelines for first-line regimens were in accordance with WHO guidelines with the addition of abacavir $(\mathrm{ABC})+3 \mathrm{TC}$ (or FTC) + EFV regimen. ${ }^{11}$

\section{Statistics}

The sample size required was calculated using the public health statistical programme Epi Info ${ }^{\mathrm{TM}} 7$. The population size was 9000 as this is the number of HIV-positive patients who attend the cART outpatient clinic at Ndola Central Hospital. The expected frequency of adherence to WHO and Zambian Ministry of Health cART guidelines was set at $90 \%$ for initiation of cART. This expected frequency was chosen as $90 \%$ was the NASF target for the percentage of patients eligible for cART to be on treatment by $2015 .{ }^{6}$ Using this expected frequency and confidence limits of $5 \%$ and a confidence level of $95 \%$, it was calculated that a sample size of 136 was required. Public health statistical programme Epi Info $^{\mathrm{TM}} 7$ was used for descriptive statistical analyses of this study, including calculating interquartile ranges (IQR) and standard deviations (SD).

\section{Results}

\section{Epidemiology}

A total of 221 patients attended the cART clinic during the study period. Information was collected from a total of 209 patients. The remaining 12 patients did not provide consent to participate, so they were excluded from the study. Of the patients, $60 \%$ were females and $40 \%$ males (Table 2 ). The age of the patients ranged from 15 to 70 years; the median age was 43 years (IQR: 36-49); and the mean age was 42 years $(\mathrm{SD} \pm 11)$. The median age that patients were started on cART was 36 years (IQR: $30-43$ ); for men, this was 40 years (IQR: 34-48) and for women it was 34 years (IQR: 29-40).

\section{Primary outcomes}

Of the 209 patients in this audit, 204 met the eligibility criteria through clinical stage or immunological criteria for cART according to the $2013 \mathrm{WHO}$ and Zambian cART guidelines. This was based upon whether patients currently met eligibility criteria or had previously been started on cART according to the guidelines at the time of initiation (Table 1). Four patients had been started on cART previously despite never meeting 2013 cART eligibility criteria. The remaining

\begin{tabular}{|c|c|c|c|c|c|c|}
\hline \multirow{2}{*}{$\begin{array}{l}\text { Patient age } \\
\text { groups (years) }\end{array}$} & \multicolumn{2}{|c|}{ Number of men } & \multicolumn{2}{|c|}{ Number of women } & \multicolumn{2}{|c|}{ All patients } \\
\hline & $n$ & $\%$ & $n$ & $\%$ & $n$ & $\%$ \\
\hline$<25$ & 5 & 6 & 16 & 12.5 & 21 & 10 \\
\hline $25-34$ & 4 & 5 & 17 & 13.5 & 21 & 10 \\
\hline $35-44$ & 25 & 30 & 49 & 39 & 74 & 35.5 \\
\hline $45-54$ & 29 & 35 & 35 & 28 & 64 & 30.5 \\
\hline $55-64$ & 18 & 22 & 7 & 5.5 & 25 & 12 \\
\hline$\geq 65$ & 2 & 2 & 2 & 1.5 & 4 & 2 \\
\hline All age groups & 83 & 40 & 126 & 60 & 209 & - \\
\hline
\end{tabular}

patient was clinical stage I, but did not have a CD4 count since diagnosis; therefore, it was impossible to determine their cART eligibility. One hundred and two patients met both immunological and clinical criteria, three patients met only clinical criteria and 99 patients were eligible on immunological criteria alone (Table 3).

Of the 204 patients who met eligibility criteria, 202 were currently on or had just been started on cART. For the two remaining patients, one was on tuberculosis (TB) treatment and a clinical decision had been made to delay cART initiation; and the other was presenting to the clinic for the first time. The time since initiation of cART ranged from 0 to 200 months, with a median time of 78 months (IQR: 49-96).

There were only two patients (1\%) on cART who were eligible for treatment according to the 2013 cART guidelines but would not have been eligible for treatment under the WHO 2010 cART guidelines as their clinical stage was less than III and CD4 count between 350 cells $/ \mathrm{mm}^{3}$ and 500 cells $/ \mathrm{mm}^{3}$. There were 27 patients (13\%) who were eligible according to 2010 WHO ART guidelines but would not have been eligible under 2006 WHO ART guidelines as their clinical stage was I or II and their CD4 count was between 200 cells $/ \mathrm{mm}^{3}$ and $350 \mathrm{cell} / \mathrm{mm}^{3}$.

The WHO clinical stage of HIV-related illness was available for all 206 patients who were started on cART at the time of initiation (Figure 1). The clinical stages of patients initiated on cART were as follows: $28 \%(58 / 206)$ clinical stage I; $21 \%$ $(43 / 206)$ clinical stage II; $36 \%(74 / 206)$ clinical stage III and $15 \%(31 / 206)$ clinical stage IV. The majority of patients starting cART treatment were clinical stage III or IV, meaning that they were eligible for treatment through the clinical criteria alone.

CD4 count results at initiation of cART were available for 181 of 206 patients and the range was from 1 cells $/ \mathrm{mm}^{3}$ to 626 cells $/ \mathrm{mm}^{3}$; the median was 147 cells $/ \mathrm{mm}^{3}$ (IQR: $84-242$ ) and the mean was 168 cells $/ \mathrm{mm}^{3}(\mathrm{SD} \pm 117$ ) (Figure 2$)$. Ninety five per cent $(172 / 181)$ of the patients had a CD4 count of below 350 cells $/ \mathrm{mm}^{3}$ at initiation of cART, the $2010 \mathrm{WHO}$ criteria for starting CART. Ninety eight per cent $(178 / 181)$ of patients had a CD4 of less than 500 cells $/ \mathrm{mm}^{3}$; this is the level set by the 2013 WHO ART guidelines and the 2013 Zambian cART guidelines. The majority of patients were started on cART soon after diagnosis as they were eligible for treatment at diagnosis, $73 \%$ of patients were started on cART within one month of diagnosis.

TABLE 3: Patients meeting 2013 combination antiretroviral therapy clinical or immunological eligibility criteria.

\begin{tabular}{lcc}
\hline 2013 ART eligibility criteria met & $\boldsymbol{n}$ & $\mathbf{\%}$ \\
\hline $\begin{array}{l}\text { Number of patients meeting both clinical and immunological } \\
\text { criteria (\%) }\end{array}$ & 102 & 49 \\
Number of patients meeting clinical criteria alone (\%) & 3 & 1 \\
Number of patients meeting immunological criteria alone (\%) & 99 & 47 \\
Number of patients not meeting eligibility criteria (\%) & 5 & 2 \\
Total number of patients & 209 & - \\
\hline
\end{tabular}




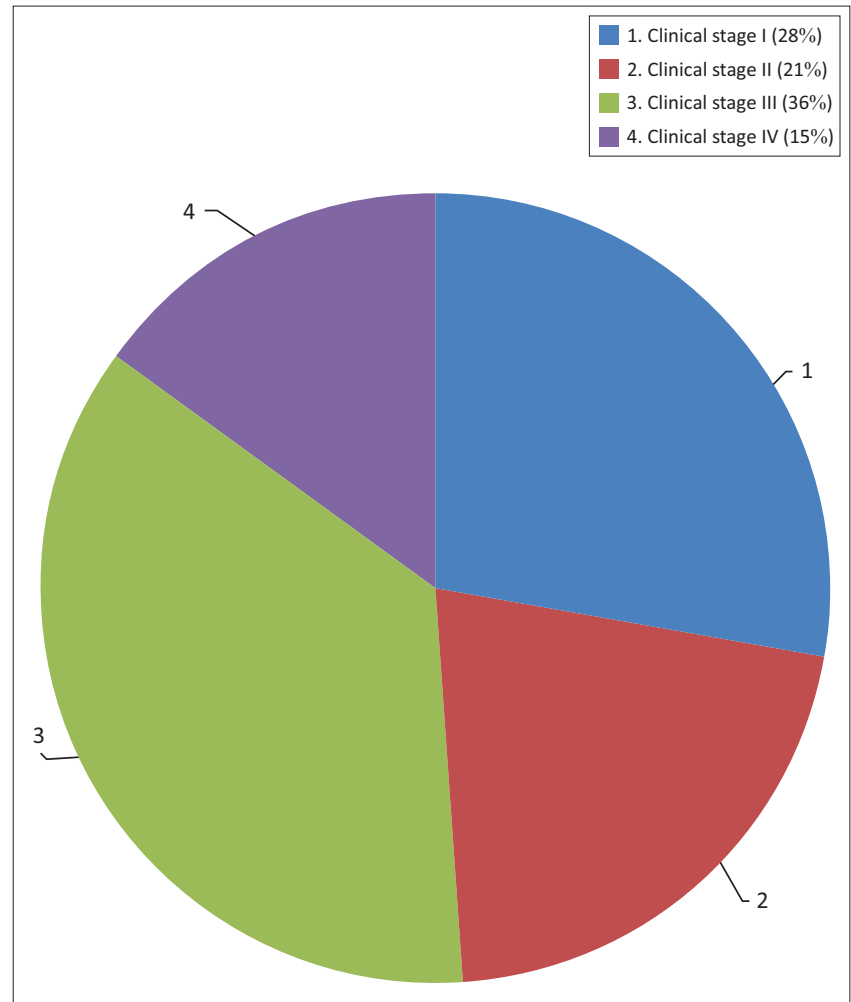

FIGURE 1: Clinical stage at initiation of combination antiretroviral therapy. $(n=206)$

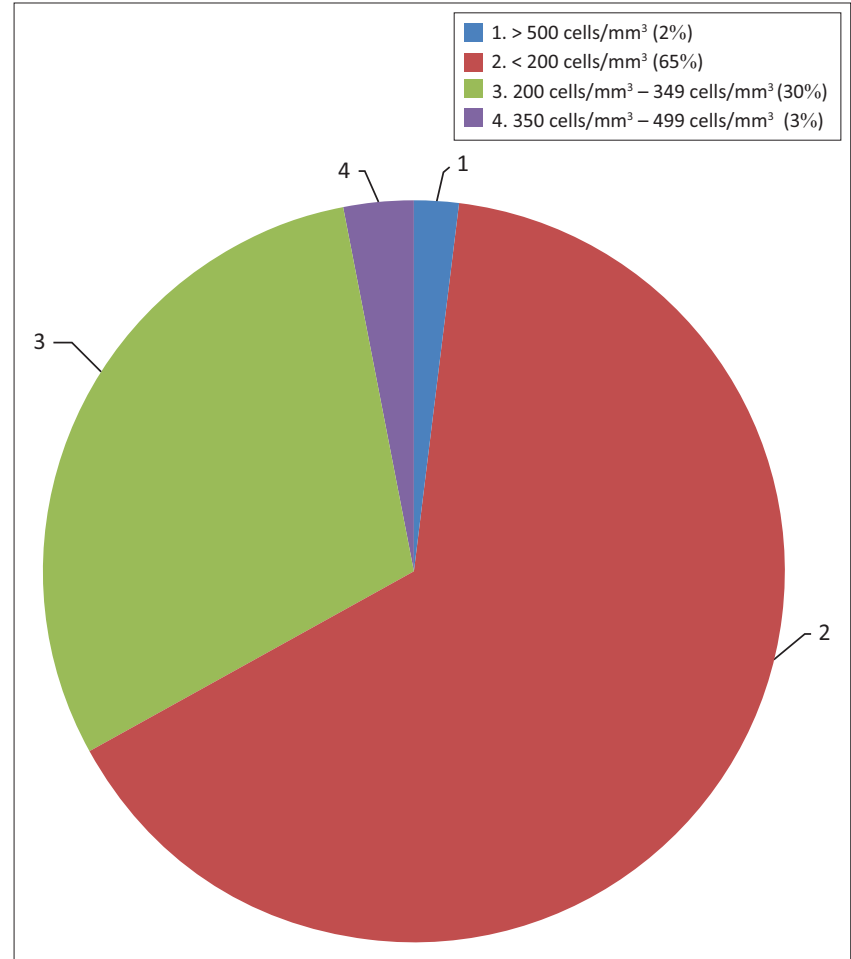

FIGURE 2: CD4 count of patients at initiation of combination antiretrovira therapy. $(n=206)$

CD4 count at initiation was stratified against clinical stage at initiation of cART to determine if clinical staging was consistent with the degree of immunosuppression; the results are shown in Table 4. No statistical analyses were performed for direct comparison of CD4 count between the groups. However, the median and mean CD4 counts of patients of all
TABLE 4: CD4 count (cells $/ \mathrm{mm}^{3}$ ) at initiation of combination antiretroviral therapy stratified against clinical stage.

Descriptive Clinical stage I Clinical stage II Clinical stage III Clinical stage IV statistics

Mean (SD) $192( \pm 102) \quad 137( \pm 91) \quad 165( \pm 133) \quad 170( \pm 128)$

Median (IQR) 185 (103-262) 124.5 (69.5-198.5) 137 (83.5-222) $145(80.75-246)$

Range $\quad 47-600 \quad 10-410 \quad 4-626 \quad 1-464$

IQR, interquartile ranges; SD, standard deviations.

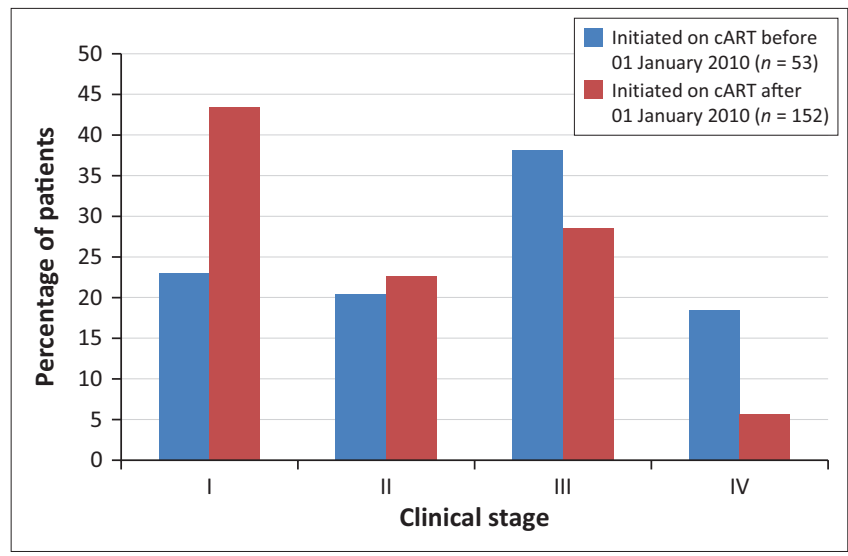

FIGURE 3: Clinical stage at initiation of combination antiretroviral therapy of patients started before 01 January 2010 and those started after 01 January 2010. $(n=206)$

clinical stages at initiation on cART do not vary greatly and there is no consistent pattern of increasing CD4 count with increasing clinical stage.

As patients in this study had been on cART for varying lengths of time, a subgroup analysis was carried out for two subgroups comprising patients initiated on cART before 2010 and those started after 01 January 2010. The WHO 2006 guidelines applied for patients initiated on cART before 2010 and the WHO 2010 guidelines for patients started on cART between 2010 and 2013 (Table 1). There were seven patients started on cART since 2013 for which the Zambian 2013 cART guidelines would apply; because of the small number, they were put in the subgroup started after 01 January 2010 rather than being given a separate subgroup. One hundred and fifty-three patients had been started on cART before 2010 and 53 since 01 January 2010; there was information on clinical stage at initiation on cART for 152 patients started before 2010 and all 53 patients in the second group (Figure 3). This was a descriptive study and no statistical analyses were performed for comparison between the two groups.

CD4 counts at initiation of cART were available for 129 of the 153 patients started before 2010, and for 52 of the 53 patients started since 01 January 2010; the results are shown in Figure 4. For the subgroup started on cART before 2010, the median CD4 count was 152 cells $/ \mathrm{mm}^{3}$ (IQR: 91-231); the range was from 3 cells $/ \mathrm{mm}^{3}$ to 572 cells $/ \mathrm{mm}^{3}$ and the mean CD4 count was 167 cells $/ \mathrm{mm}^{3}(\mathrm{SD} \pm 110)$. The subgroup started on cART since 01 January 2010 had a median CD4 count of 145.5 cells $/ \mathrm{mm}^{3}$ (IQR: 68.25-254.5), a range from 1 cells $/ \mathrm{mm}^{3}$ to 626 cells $/ \mathrm{mm}^{3}$ and a mean of 169 cells $/ \mathrm{mm}^{3}(\mathrm{SD} \pm 134)$. 


\section{Secondary outcomes}

The majority of patients $(87 \% ; 180 / 206)$ were currently on first-line treatment regimens. Eighty three per cent (149/180) of first-line regimens were those recommended by the 2013 Zambian ART guidelines and 81\% (145/180) by WHO 2013 guidelines (Table 5). Sixty three per cent $(114 / 180)$ of patients on first-line regimens were on the TDF + FTC + EFV regimen which is recommended in preference to other first-line regimens by both the 2013 WHO guidelines and the 2013 Zambian cART guidelines.

Fifty nine per cent of patients had their cART regimens changed at least once. Fifty per cent of regimen changes were because of side effects of which peripheral neuropathy and lipodystrophy were the most common. The second most frequent reason for regimen change was treatment failure $(22 \%)$, with immunological treatment failure making up $72 \%$ of this total. The third largest group (21\%) had their treatment changed to keep regimens in accordance with the Zambian cART guidelines.

Twenty nine per cent of the patients reported having one or more side effects from their current cART regimens. The most common side effects were peripheral neuropathy (in 6\% of patients) followed by nausea and/or vomiting (5\%) and then dizziness (4\%) Peripheral neuropathy was most common in patients on cART regimens containing stavudine.

Of the patients, 202 reported their adherence to cART regimens; $78 \%$ reported perfect adherence, indicating that they had not missed a single dose in the last month; $13 \%$

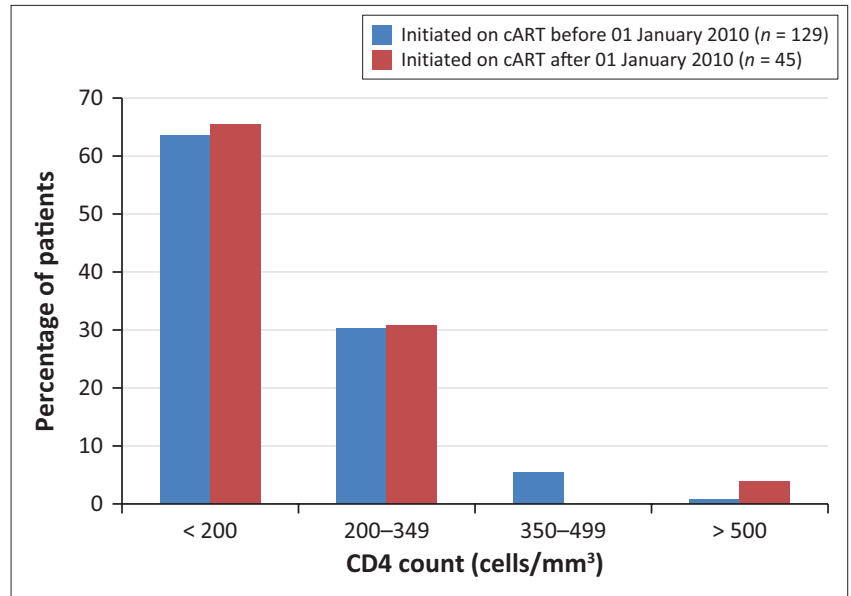

FIGURE 4: CD4 count at initiation of combination antiretroviral therapy of patients started before 01 January 2010 and those started after 01 January 2010.

TABLE 5: First-line combination antiretroviral therapy regimens currently being used.

\begin{tabular}{lc}
\hline First-line regimens & Number of patients on each first-line regimen \\
\hline TDF + FTC + EFV & 114 \\
TDF + FTC + NVP & 31 \\
ABC + 3TC + EFV & 4 \\
First-line regimens not in & 31 \\
accordance with guidelines & \\
\hline
\end{tabular}

ABC, abacavir; EFV, efavirenz; FTC, emtricitobine; NVP, nevirapine; TC, lamivudine; TDF, tenofovir disoproxil fumarate. reported good adherence, meaning that they had missed one dose in the last month; 6\% reported average adherence, meaning that they had missed one dose in the last week; and $2 \%$ reported poor adherence, meaning that they had missed more than one dose in the last week (Table 6).

The most prevalent risk factor amongst the study population was multiple concurrent sexual partners, which was reported by $28 \%$ of participants; other risk factors were first sexual contact $<15$ years (13\%) and transactional sex (11\%) (Table 7). Forty eight per cent of participants said they always or usually used condoms, while $48 \%$ reported they occasionally or never used condoms, with the remaining patients reporting abstinence over condom use (Table 8).

\section{Discussion}

Ninety eight per cent of patients were eligible for cART using current guidelines, and of these, $99 \%$ were currently on cART. These results show that the cART clinic was adhering closely to the $2013 \mathrm{WHO}$ and Zambian national guidelines on initiation of cART.

At initiation on CART, the majority of patients were stage III or IV (Figure 1) and thus eligible for treatment on clinical stage alone. ${ }^{4,11}$ The CD4 counts when patients were started on cART were generally very low (Figure 2 ), the median being 147 cells $/ \mathrm{mm}^{3}$, well below 500 cells $/ \mathrm{mm}^{3}$ the level of eligibility for cART under the 2013 guidelines. These results show that most patients had advanced disease before they were started on treatment, which is likely to have a negative impact on health outcomes. . $^{13,14,15}$

CD4 count was stratified against clinical stage to assess if clinical stage was consistent with the degree of immunosuppression. It would be expected that the degree of immunosuppression (measured by decreasing CD4 count) would increase as the clinical stage increased; however, there did not appear to be a clear correlation between the clinical stage and CD4 count in this study (Table 4). This could be because patients all clinical stages had severe immunosuppression (CD4 $<200$ cells $/ \mathrm{mm}^{3}$ ), meaning that even those who were asymptomatic would also be at high risk of developing diseases or symptoms of clinical stage III

TABLE 6: Reported adherence to combination antiretroviral therapy regimens.

\begin{tabular}{|c|c|c|c|c|c|c|c|c|}
\hline \multirow{2}{*}{$\begin{array}{l}\text { Reported } \\
\text { adherence }\end{array}$} & \multicolumn{2}{|c|}{ Perfect } & \multicolumn{2}{|c|}{ Good } & \multicolumn{2}{|c|}{ Average } & \multicolumn{2}{|c|}{ Poor } \\
\hline & $\%$ & $n$ & $\%$ & $n$ & $\%$ & $n$ & $\%$ & $n$ \\
\hline $\begin{array}{l}\text { Percentage } \\
\text { of patients }\end{array}$ & 78 & $158 / 202$ & 13 & $26 / 202$ & 6 & $13 / 202$ & 2 & $5 / 202$ \\
\hline
\end{tabular}

TABLE 7: Risk factors for Human Immunodeficiency Virus.

\begin{tabular}{lcc}
\hline Risk factors for HIV & \multicolumn{2}{c}{ Number of patients } \\
\cline { 2 - 3 } & $\boldsymbol{n}$ & $\mathbf{\%}$ \\
\hline MSM & $4 / 209$ & 2 \\
IVDU & $2 / 209$ & 1 \\
$<15$ at first sexual contact & $27 / 209$ & 13 \\
Transactional sex & $22 / 209$ & 11 \\
Multiple concurrent partners & $59 / 209$ & 28 \\
\hline
\end{tabular}

MSM, Men who have sex with men; IVDU, Intravenous drug use 
TABLE 8: Reported condom use.

\begin{tabular}{|c|c|c|c|c|c|c|c|c|c|c|}
\hline \multirow[t]{2}{*}{ Reported condom use } & \multicolumn{2}{|c|}{ Always } & \multicolumn{2}{|c|}{ Usually } & \multicolumn{2}{|c|}{ Occasionally } & \multicolumn{2}{|c|}{ Never } & \multicolumn{2}{|c|}{ Not applicable } \\
\hline & $n$ & $\%$ & $n$ & $\%$ & $n$ & $\%$ & $n$ & $\%$ & $n$ & $\%$ \\
\hline Number of patients & $69 / 209$ & 33 & $32 / 209$ & 15 & $55 / 209$ & 26 & $45 / 209$ & 22 & $8 / 209$ & 4 \\
\hline
\end{tabular}

or IV. It could also suggest that there were inaccuracies in how a patient's clinical stage was assessed.

Patients attending the clinic had been on cART for varying time periods; therefore, a subgroup analysis was performed. No statistical tests were performed to compare the subgroups; so it is not possible to make meaningful comparisons between the two subgroups. However, it appeared that a lower proportion of patients started on cART after 01 January 2010 were clinical stage III or IV than those started before 2010 (Figure 3); this could suggest that patients were being diagnosed earlier. Further research is needed with statistical power to test if there has been progress towards earlier initiation of cART.

Since this audit was conducted, the WHO released additional guidelines in 2015 which stipulate that cART should be started in all patients with HIV irrespective of their clinical stage or CD4 count. This would have affected the cART eligibility for five patients in this audit; however, four of these patients had already been started on cART despite not meeting eligibility criteria; the reasons for these patients being initiated on CART were not clear. It appears that late presentation to the CART clinic is the main factor delaying initiation of CART, as once patients attended the cART clinic their eligibility was assessed according to current guidelines and those that were eligible started on cART within a short period, the majority within a month of diagnosis.

Late initiation on CART may occur because of delay in referral to cART services from HIV counselling and testing (HCT) facilities, or late diagnosis as a result of low uptake of HCT programmes. This may mean that patients are only tested for HIV once they become symptomatic by which stage the patient's illness has already progressed significantly. Recent data have shown an increase in HIV testing in public health facilities. Further research is needed to investigate if these improvements in HCT result in earlier initiation on cART. It is important that these improvements in HIV testing are monitored to ensure they are maintained, and further progress made. In addition, good education about HIV is needed to improve uptake of HCT by informing people of the importance of early diagnosis and assisting early identification of symptoms associated with HIV. HCT facilities also need to have good referral systems to cART services for HIV-positive people as this can be another source of delay in initiation of cART. Early initiation of treatment can improve morbidity and mortality in patients with HIV and additionally reduce the infectivity, minimising further transmission. ${ }^{13,14,15,16}$

A large majority (87\%) of patients on cART were currently on first-line regimens of which $83 \%$ were in accordance with the Zambian Ministry of Health guidelines (Table 3). There seems to be a concerted effort to change patients onto regimens recommended by the national guidelines, with patients recently started on cART being initiated on the TDF + FTC + EFV regimen and patients on older regimens being changed to regimens in accordance with the Zambian cART guidelines; this is a common reason for regimen change. Just under one third of patients experienced at least one side effect on their current cART regimen, the most common being peripheral neuropathy, which was most common in those on stavudine regimens. The 2013 guidelines no longer recommend regimens with stavudine; this should help reduce the incidence of peripheral neuropathy as a side effect of ARVs.

The most common reported risk factor for HIV in this study was having multiple concurrent partners with $28 \%$ of patients reporting this (Table 5). In the Zambian demographics and health survey (ZDHS) from 2013 to $2014,1.0 \%$ of women and $12.8 \%$ of men aged 15-49 reported having concurrent sexual partners within the last 12 months. ${ }^{17}$ The prevalence of concurrent sexual partners appears higher in patients attending the ART clinic than in the general population in Zambia. In this study, $11 \%$ of patients reported transactional sex; in the ZDHS from 2013 to $2014,12.8 \%$ of men reported paying for sex; however, there is limited information on the number of sex workers in Zambia. ${ }^{17}$ Thirteen per cent of patients reported early sexual contact, the ZDHS from 2013 to 2014 found $11.7 \%$ of women and $16.2 \%$ of men aged $15-24$ years reported sexual contact below the age of 15 years; this is similar to the prevalence in our study. Two per cent of patients in this study reported men who have sex with men (MSM) and 1\% intravenous drug use (IVDU); there is currently very limited information on these key populations. However, the population council and partners are currently conducting research in this area of which the results are awaited. ${ }^{18}$ In addition, almost half of the patients in the study reported that they only used condoms infrequently (Table 6). The ZDHS in 2013-2014 reported that 23.1\% of HIV-positive people aged 15 years - 49 years used a condom in their last sexual intercourse and $12.1 \%$ reported not using a condom. ${ }^{17}$ Low condom usage is likely to result in higher transmission rates in Zambia. It is likely improved education programmes including those targeted at groups of high risk for HIV would be valuable in limiting the further spread of HIV. The most recent Zambia country report on HIV reported that comprehensive knowledge of HIV had increased. ${ }^{5}$ However, further improvements regarding HIV knowledge are crucial and education interventions targeting people with HIV could be particularly effective in reducing transmission.

Other studies have looked at stage of initiation on cART in sub-Saharan Africa and had similar findings. In a study by Mhozya et al. in Tanzania with 366 patients which took place in 2013, 63\% of patients presented to the ART clinic with clinical stage III or IV, and $42 \%$ with a CD4 count below 200 cells $/ \mathrm{mm}^{3} .{ }^{19}$ Kigozi et al. conducted a study in Uganda in 2007 with 2584 patients where $40 \%$ of patients were stage III or IV when started on cART; both these studies showed late 
initiation of cART; further suggesting this is a significant problem..$^{20}$

There were a number of limitations to this study. No sampling interval or random sampling was used; instead all patients attending the cART clinic during the study period were invited to participate. It would have been preferable to use a systematic or random sampling technique over a longer period to obtain the same sample size. This error in sampling technique may have resulted in an unrepresentative sample, and thus biased the results. From the population attending the cART outpatient clinic (9000) for Ndola Central Hospital, if all patients were seen once every year, there would be an expected attendance of around 1000 patients over the six week period of the study; however, there were only 221 patients who attended the cART clinic during the study period. It is not clear why the number of patients attending the clinic during the study period was so low compared with the expected number; this could be because of non-attendees at the clinic, or the time of year of the study (the end of rainy season) which could mean patients are prevented from attending the clinic. This may make the sample less representative of the population who attend the cART clinic, particularly as there could be bias towards patients who regularly attend the cART clinic. Some interviewees had problems understanding the questions because of language difficulties; some of the interviews were conducted with the help of translators; it is possible that these factors could lead to inaccurate answers. In some cases, information was missing from the notes, and where it was given, dates were sometimes omitted; this made it difficult to obtain a full data set for every patient, thus reducing reliability of results. There were no statistical analyses of reported risk factors which reduce the significance which can be attached to these results. Results on self-reported adherence to CART did not use a prior validated measure of adherence; this may reduce the reliability and comparability of these results. In addition, self-reported adherence often overestimates medication adherence. ${ }^{21}$

\section{Conclusion}

Early initiation of cART can stop disease progression and improve long-term health outcomes. In 2013, new WHO and Zambian national guidelines on cART expanded the eligibility criteria for cART treatment. This study evaluated and audited the use of CART at the outpatient cART clinic at Ndola Central Hospital in Ndola, Zambia, comparing and analysing results against the 2013 Zambian cART guidelines and the 2013 WHO ART guidelines.

The study showed that almost all patients eligible for cART according to the 2013 cART guidelines were on treatment, the majority on appropriate cART regimens; however, many patients were initiated on cART late according to clinical and immunological criteria. This late diagnosis may be because of a lack of uptake of HCT; however, there have been improvements in HCT in Zambia over the past few years. Further research is also needed to assess the impact of increased HCT on earlier initiation of CART. It is important that HIV testing is monitored closely to ensure that testing levels are maintained and further increased, as well as good referral systems to cART clinics.

In conclusion, almost all eligible patients who attended the clinic were started on cART and in the majority of cases cART treatment was initiated soon after diagnosis. Initiation of cART tends to be late according to immunological and clinical criteria, which is probably because of late diagnosis of HIV. Interviews of patients highlighted the limited awareness of the influence of sexual practices and the need to take precautions to avoid the spread of HIV. Progress in tackling HIV requires continued expansion of HCT coupled with education programmes targeting groups at high risk.

\section{Ethical consideration}

A research proposal was approved by the hospital ethics committee. Each patient was assessed to check that they understood what participation in the study would involve. Written or verbal consent was obtained before participation in the study as explained above. Patients were informed that data that would be collected both from interviews and from their clinical records. All information was kept confidential and anonymous.

\section{Acknowledgements}

We would like to thank Dr Sebastian Chinkoyo for helping arrange this project in Ndola Central Hospital, and all the staff at the outpatient cART for their help during the project, Richard Martini for statistical and methodological advice, and also Marian Martin and Colin Martin for reading through this study.

\section{Competing interests}

The authors declare that they have no financial or personal relationships which may have inappropriately influenced them in writing this article.

\section{Authors' contributions}

T.M. hypothesised and organised the clinical audit and did data collection, data analysis and writing up of the study. M.M. was the supervisor of the study, assisted in organising clinical audit, read through the article and provided advice for analysis and write-up for the study.

\section{References}

1. UNAIDS. UNAIDS fact sheet 2016 [homepage on the Internet]. Geneva, Switzerland: UNAIDS; 2016 [cited 2016 Jan 10]. Available from: http://www. unaids.org/sites/default/files/media_asset/UNAIDS_FactSheet_en.pdf

2. WHO. Antiretroviral therapy for HIV infection in adults and adolescents: Recommendations for a public health approach: 2010 revision [homepage on the Internet]. Geneva, Switzerland: World Health Organization; 2010 [cited 2016 Dec 18].Availablefrom:http://whqlibdoc.who.int/publications/2010/9789241599764 eng.pdf?ua=1

3. Finch RG, Irving WL, Moss P, Anderson J., Infectious diseases, tropical medicine and sexually transmitted infection. In: Kumar P, Clark M, editors, Kumar \& Clark's clinical medicine. 7th ed. Amsterdam, Netherlands: Elsevier, 2009; pp. 184-187.

4. WHO. Consolidated guidelines on the use of antiretroviral drugs for treating and preventing HIV infection [homepage on the Internet]. Geneva, Switzerland: World Health Organization; 2013 [cited 2013 Dec 18]. Available from: http://www.who. int/hiv/pub/guidelines/arv2013/en/ 
5. National AIDS Council. Zambia country report: Monitoring the declaration of commitment on HIV and AIDS and the universal access [homepage on the HIV and AIDS; 2015 [cited 2016 Feb 17]. Available from: http://www.unaids.org/ sites/default/files/country/documents/ZMB narrative_report_2015.pdf

6. National AIDS Council. Zambia country report: Monitoring the declaration of commitment on HIV and AIDS and the universal access; Biennial Report [homepage on the Internet]. Submitted to the United Nations General Assembly Special Session on HIV and AIDS. Lusaka, Zambia: Zambia Ministry of Health; 2012 [cited 2013 Dec 18]. Available from: http://www.unaids.org/en/dataanalysis/knowyourresponse/co

7. Mah TL, Halperin DT. Concurrent sexual partnerships and the HIV epidemics in Africa: Evidence to move forward. AIDS Behav. 2010 Feb;14(1):11-16. https://doi. org/10.1007/s10461-008-9433-x

8. Alary $\mathrm{M}$, Lowndes $\mathrm{CM}$. The central role of female sex worker in the dynamics of heterosexual HIV transmission in sub-Saharan Africa. AIDS. 2004;18(6):945-947. https://doi.org/10.1097/00002030-200404090-00013

9. Marseille E, Giganti MJ, Mwango A, et al. Taking ART to scale: Determinants of the cost and cost-effectiveness of antiretroviral therapy in 45 clinical sites in Zambia. PLoS One. 2012;7(12):e51993. https://doi.org/10.1371/journal. pone.0051993

10. Stringer JS, Zulu I, Levy J, et al. Rapid scale-up of antiretroviral therapy at primary care sites in Zambia: Feasibility and early outcomes. JAMA. 2006;296(7):782-793. https://doi.org/10.1001/jama.296.7.782

11. Zambian Ministry of Health. Zambia consolidated guidelines for treating and preventing HIV 2014 [homepage on the Internet]. Lusaka, Zambia: Ministry of Health; 2013 [cited 2016 Oct 3]. Available from: http://www.emtct-iatt.org/wpcontent/uploads/2016/01/ZambiaARTguidelines20131391802142.pdf

12. WHO. Guidelines on when to start antiretroviral therapy and on pre-exposure prophylaxis for HIV [homepage on the Internet]. Geneva, Switzerland: World Health Organization; 2015 [cited 2016 Feb 17]. Available from: http://apps.who. int/iris/bitstream/10665/186275/1/9789241509565_eng.pdf
13. Kitahata MM, Gange SJ, Abraham AG, et al. Effect of early versus deferred antiretroviral therapy for HIV on survival. N Engl J Med. 2009:360:1815-1826. https://doi.org/10.1056/NEJMoa0807252

14. Emery S, Neuhaus JA, Phillips AN, et al. Major clinical outcomes in antiretroviral therapy (ART)-naïve participants and in those not receiving ART at baseline in the SMART study. J Infect Dis. 2008;197(8):1133-1144. https://doi.org/10.1086/586713

15. Sterne JA, May M, Costagliola $D$, et al. Timing of initiation of antiretroviral therapy in AIDS free HIV-1-infected patients: A collaborative analysis of 18 HIV cohort studies. Lancet. 2009;373(9672):1352-1363. https://doi.org/10.1016/S01406736(09)60612-7

16. Cohen MS, Chen YQ, McCauley M, et al. Prevention of HIV-1 infection with early antiretroviral therapy. N Engl J Med. 2011;365:493-505. https://doi.org/10.1056/ NEJMoa1105243

17. Central Statistical Office (CSO) [Zambia], Ministry of Health (MOH) [Zambia], ICF International. Zambia Demographic and Health Survey 2013-14 [homepage on the Internet]. Rockville, MD: Central Statistical Office, Ministry of Health, ICF International; 2014.

18. Population Council. Identifying key populations in Zambia [homepage on the Internet]. New York [cited 2017 Jul 27]. Available from: http://www.popcouncil. org/research/identifying-key-populations-in-zambia

19. Mhozya H, Bintabara D, Kibusi S, Neilson E, Mpondo BC. Late-stage disease at presentation to an HIV clinic in eastern Tanzania: A retrospective cross-sectional study. Malawi Med J [serial online]. 2015 [cited 2017 March 19];27(4):125-127. Available from: http://www.ncbi.nlm.nih.gov/pmc/articles/PMC4761702

20. Kigozi IM, Dobkin ML, Martin JN, Geng EH. Late disease stage at presentation to an HIV clinic in the era of free antiretroviral therapy in sub-Saharan Africa. J Acquir Immune Defic Syndr. 2009;52(2):280. https://doi.org/10.1097/OAl.0b013e3181ab6eab

21. Hales G, Mitchell J, Smith DE, Kippex S. Validity of patient questioning versus pill count as an assessment of compliance. Program and abstracts of the 12th World AIDS Conference; 1998 June 27, Geneva: Marathon Multimedia [abstract 32373]. 